\title{
An ecosystem-wide study of a complex ESL program through activity theory and semiotics
}

\author{
Alan Wai Lun Lai \\ Department of Applied Psychology, Division of Science and Technology, Beijing Normal University/Hong Kong Baptist University, \\ United International College, 28, Jinfeng Road, Tangiawan, Zhuhai, Guangdong, China
}

\section{Email address:}

alanlai@uic.edu.hk

\section{To cite this article:}

Alan Wai Lun Lai. An Ecosystem-Wide Study of a Complex ESL Program through Activity Theory and Semiotics. International Journal of Language and Linguistics, Vol. 1, No. 2, 2013, pp. 54-69. doi: 10.11648/j.ijl1.20130102.13

\begin{abstract}
The purpose of this study was to investigate how a learning environment went about for second language (L2) learning. Drawing on an ecological perspective, this work conceives an after-school program aimed for promoting a group of secondary-school students' L2 learning as an ecosystem or a whole that was highly complex due to interrelated layers of any contextualized details. In this context, to understand how a group of L2 learners regulated their L2 learning strategies in the environment became a complexity issue. To take on this challenge, this study turned to activity theory in terms of semiotics of signs to transforming any contextualized details - drawn from observations over 12 lessons - into an interwoven set of ecosystem-wide characteristics found relevant to L2 learning. The research focused on a group of four secondary-school students in Hong Kong, in an after-school home environment over 12 lessons, examining a range of teaching-learning activities. Data consisted of videotaping and field notes during and after each class based on a participant perspective through observations. As a result, the L2 learning environment was on the one hand described to be one where meaning-making signs were diversified and interrelated while maintaining their informational dynamism. On the other hand, active engagement, guidance-oriented regulation and activity aims were also found to function together progressively for (1) reaching specific L2 meaning-making goals closer and closer and (2) increasing opportunities for making meaningful contributions to each other's mental understanding in L2.
\end{abstract}

Keywords: Ecological Perspective, Activity Theory, Semiotics, Second Language Learning, Complexity Management, Ecosystem

\section{Introduction}

The current paper's research phenomenon of interest is in response to van Lier's (2004) urge - from an ecological approach - to preserve contextualized sources of data on a full scale when studying a second language (L2) learning environment and the learners within. What van Lier argues is tied to the notion that L2 learning is a contextualized process in which learners are actively engaged and dynamically provided with diverse learning opportunities in meaningful activities or interactions situated in a natural yet highly complex environment (Garner, 2004; also see Bronfenbrenner, 1976). If a study is to understand how L2 learning occurs experimentally, what would become problematic is all learning processes being decontextualized by (1) switching learning opportunities to pre-determined or rigidly-coded variables, (2) turning active engagement into experimental manipulation, (3) replacing a meaningful activity of interest into a contextblind setting of inquiries, and/or (4) making contextualized data (e.g., real life data) become unavailable for analysis. In short, van Lier's main concern is a substandard of investigation caused by losses of original contexts. In this regard, to preserve contexts by hooks or by crooks, like how an ecologist preserves samples in a tropical rainforest prior to shedding light on their natural processes, is what van Lier advocates.

Based on van Lier's ecological perspective, this study aimed at investigating how the L2 learning environment went about when the learners were embedded in a diversity of learning opportunities. However, the issue of managing complexities stemming from a full-scale preservation of multifaceted contextualized details and their interrelationships - let alone a variety of interwoven physical, social, individual, semiotic and informational contexts - translates into an investigation challenge. This paper sets off to revolve around this attempt. 
To work with the issue of complexities, this paper draws on a theoretical framework based on theories of activity and signs, a systematic strategy to describing an afterschool program involving a small group of secondary school students in Hong Kong, or one that gives emphasis to the emergence of contextualized details, collective activities and interpersonal engagement for L2 learning.

\section{Ecological Relations}

When seeing the learning system under concern, this paper highlights the "ecological relations" between children's L2 learning and their immediate environment. On the one hand, the "ecological relations" for the study of L2D refer to the totality of contextual or meaningful relationships between an L2 learner and the L2 community situated in an L2 learning environment. On the other hand, the study was conducted to treat an L2 learning environment as unique in the sense that the entire learning contexts were embedded in a variety of activities and objects specifically determined and co-constructed by all the study participants in an after-school home environment.

To shed light on the ecological relations of the learning environment under concern, the next section gives rise to the conceptual framework of this paper which involves Engeström's (1987) activity theory with semiotic (i.e., meaning-making) signs as its infrastructure.

\section{Complexity Management of Contextualized Data}

This section is with the goal of presenting the conceptual framework grounded on the literature of methodologies associated with managing efforts towards the complexity issue or complexity management of contextualized data. Reviewing them one from each other helps contextualize rationales for the need to relating activity theory to semiotic signs, out of which the theoretical framework of this paper takes into shape.

\subsection{Engeström's Activity Theory}

Engeström's (1987) activity theory is developed from the original version formulated by Vygotsky (1978) which focuses on the activity relationship between a subject and an object with mediating artefacts (Thorne, 2000). Engeström (1987) sees Vygotsky's focus on an activity as too narrow and thus expands its unit of analysis from a subject basis to an activity scale. With this expanded scale, Engeström looks no longer at one subject at a time but the whole complex of inter-linking relationships between the subject and the related "others" in an activity full of mediating tools, artefacts and rules (Engeström, 1999). The enlargement of the lens thus brings in a wider angle of voices and views in a community where the subject and the related "others" interact with each other for a goal-oriented activity.

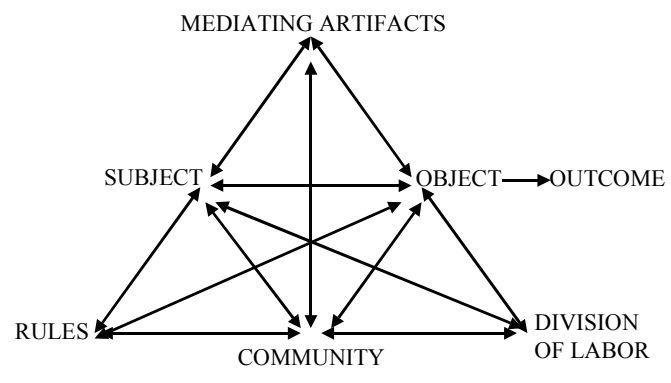

Figure 1.Engeström's Activity System Model (Engeström, 1999, p. 31)

Figure 1 shows the schematic model of Engeström's activity system. In the model, the role of artefacts (e.g., a computer) is to mediate the relationship between a subject (e.g., a student) and an object (e.g., a learning task).

This mediational feature is the original formulation of an activity developed by Vygotsky. Other mediational features are also incorporated into the system. One is that subjects and their others in the community (e.g., a home school) are mediated by some rules (e.g., school rules). Another meditational feature is the notion that the way in which a subject and the subject's community are oriented to a certain goal is mediated by a division of labour; this division of labour brings in a diversity of ranks, positions and duties among the community. These meditational features also relate to each other to form the backbone of Engeström's activity theory (Engeström, 1999). In terms of methodology, the mediational features are used to reconstruct the contexts of a construct (e.g., L2 learning) into a highly contextualised activity.

\subsection{Activity Theory as a Complexity Management Model}

Engeström's activity theory has been widely adopted as a heuristic framework to dealing with highly complex contexts (i.e., the complexity) of L2 learning and practices in various educational settings by reconstructing them (e.g., Boer, Baalen, \& Kumar 2002; Buell, 2002; Elleuch, Bellamine-Bensaoud, \& Ben Ahmed, 2006; Engeström, 1999; Li, 2013; Scanlon \& Issroff, 2005). For example, Scanlon \& Issroff (2005) attempted to evaluate learning technology and examine the learning and teaching experiences in a technology-mediated setting regarded to be highly complex (see p. 432). Responding to this complexity issue, the researchers chose activity theory to reconstruct the complex contexts of human-computer interaction and human-human collaboration.

In a similar vein, Elleuch et al. (2006) regarded the environment of the research setting to be highly complex, saying that it is mostly due to "the variety of disciplines addressed, and the discovery of functional and nonfunctional requirements" (p. 66). To deal with this issue, they pointed out that "activity theory [is] proposed as a generic theoretical framework which can be used to analyze complex contexts" (p. 67).

Regarding the attempt of how reconstruction of complex contexts could be accomplished, Buell (2002) strategically 
invoked different components of activity theory including newly emerged artefacts, the subject's educational practice, grading rules, the subject's identity in the subject's school community, the different social roles of the subject in different tasks, and the need of the subject to learn how to teach with technology.

The three studies above show that activity theory has been used as a complexity management model to handling the issue of complexity, echoing the comments from Gay \& Hembrooke (2004) that:

Activity theory is a holistic approach that can accommodate complexity and diversity by integrating multiple levels of analysis, diverse and multidimensional activities, and various contextual features.... (p. 14).

As well as this strength to reconstructing complex contexts, activity theory also brings together human and non-human entities into a meaning-making relationship. Since it is humans who turn non-human entities into cultural-historical artefacts, understanding culturalhistorical activities means examining the dynamic processes of how humans regulate, distribute and use artefacts as making meanings with the world. Such a meaning-making activity that takes cultural-historical processes into account is what activity theory mainly focuses on.

This paper's theoretical framework is in part based on four cultural-historical processes informed by activity theory, namely:

(1) genesis (e.g., a process of how artefact emerge through actions of humans),

(2) regulation (e.g., a process of how humans regulate artefacts for meaning-making with the world),

(3) distribution (e.g., a process of how humans distribute artefacts for meaning-making with the world), and

(4) usage (e.g., a process of how humans use artefacts for meaning-making with the world).

This cultural-historical orientation serves as the main architecture of the theoretical framework; however, it is yet complete. The next three subsections continue to explain the inclusion of semiotics to the framework as its infrastructure.

\subsection{Activity Theory in Terms of Semiotics of Signs}

In light of the strengths of activity theory, it is however not without critiques. Wiredu $(2004,2005)$ notices that one of activity theory's strengths in terms of its ability to dealing with complexity by reconstructing complex contexts is paradoxically a weakness. The reason is that when dealing with the issue of complexity, researchers are in fact trying to reconstruct the highly complex contexts in which the actors achieve a goal with the mediations of a cultural artefact. If the mediational functions of the artefact are highly complex, any actions involved to actualize the functions would inevitably become more complex. Not only that, the contexts under study would become a lot more complicated to examine when other contexts, such as the one including the rules for the use of different tools, division of labour that determines who controls the tools at different levels and all the tasks based on the actors' historical experiences, are interlinked to the subject-toolobject complex. Wiredu (2004) criticises that such a methodology is in fact used "to enslave a subject" and "bury the subject in a multilayered-barricade-fortified underground" (see p. 104 and p. 109). In other words, what is needed is a complexity management strategy that could extract meaningful information from individual actors - or meanings of actions - when they are embedded in activityrelated processes. Out of this technical concern, this paper turns to semiotics of signs when looking for a way that could help provide meanings of actions from individuals situated in a variety of L2 activity processes.

This use of semiotic signs to provide meanings of actions is buttressed by van Lier's eco-semiotic perspective which sees language development, first or subsequent, as a semiotic progression transforming signs into more adaptive or more meaningful linguistic signs. Van Lier relates this concept about emergence of more meaningful meanings to "the social and dialogical nature of sign and language" (p. 63 ). The meaning is that when a learner encounters and acts on a sign that can afford the actor to achieve a certain meaning-making goal, the learner's sign-using actions progressively give rise to the contents of a meaning-making process. In other words, no content would come to light unless the content of a meaning-making process grows with (or should be interpreted with) the learner's sign-using actions. Therefore, merely studying the process alone without regard to what the learner does would hardly yield any productive result.

To apply the proposition of this semiotic progression of activity theory concept to the study of an L2 learning environment, this study strategically documented how an L2-based aim is achieved progressively (or contextually reconstructed) through(1) genesis, (2) regulation, (3) distribution, and (4) usage in terms of meaning-making signs (i.e., hand-in-hand through activity theory and semiotics). Systematically, L2 learning was captured as the ingredients, the raw materials out of which signs emerge and sign-using actions grow as individual learning actors manage to transform signs into more complex but meaningful meaning-making signs to satisfy certain objectives of activity and facilitate all the processes behind. In other words, it is an opportunity to see how information might become a certain form of sign, out of which signs might follow in a certain progressive way among the various processes of the activity system.

\subsection{How to Identify Signs}

Based on van Lier, all forms of activities involve signs, and all activities generate meanings. According to his semiotic-ecological approach (2004), Peirce's (1992, 1998) science of signs is the basis of all kinds of information an organism can possibly encounter for meaning-making in a natural environment. Information, seen as a certain kind of sign, is of three planes of signs: iconic, symbolic and 
indexical. On an iconic plane, information is perceived as a sign that represents some quality of an object. For example, a diagram provides some information about the abstraction of a scientific theory ${ }^{1}$. On a symbolic plane, information becomes a symbolic sign that conventionally represents some properties of an object. For example, the word "cat" represents a particular kind of animal. The meaning and the symbols are all conventionally determined. On an indexical plane, information becomes an indexical sign that actually connects to some properties of an object. For example, the smoke coming out from a burning house actually refers to a fire happening somewhere. The common thing to all the three semiotic planes is that they all possess certain meaning. ${ }^{2}$

In this study, activity-related contexts for achieving L2 learning aims were reconstructed in terms of how iconic, indexical and symbolic signs were originated, regulated, distributed and used. As such, here an imaginary example using an idiomatic expression may shed some light on how to identify the three types of signs and semiotic progression, from plane to plane, in an L2 learning environment.

An L2 learning child first hears a new expression from a teacher saying "I am going to kill the light" and sees the teacher point to the light switch and turn the light off. The child then hears the teacher ask the child to "kill the rest of the lights in the room". The child who just hears what the teacher says and does manages to respond right away and turn the rest of the lights off. In this hypothetical incident, the expression of "I am going to kill the light" is a symbolic sign since it denotes a conventional meaning. On this symbolic plane, the child is afforded the opportunity to progress to the iconic plane when the child continues to perceive the meaning of the symbolic sign available in the immediate context - seeing the light switch being pointed at and the light being turned off. On the plane, the expression is transformed into an iconic sign since it denotes some quality of what happens to the switch and the light. But when the teacher points at the light, it actually connects his expression to the light switch in the teacherstudent interaction, thus giving rise to the emergence of an indexical sign. On an indexical plane, the child's attention is driven towards the light switch (and what could go on to happen), thus making further actions to take more possibly such as responding to the teaching's request and turning the rest of lights off.

\section{Research Procedures}

In this study, four student participants aged 14 years old attended a 12-lesson L2 learning program in two twin students' home. The ultimate aim of the program was to develop the participants' L2, that is, to develop their ability to generate genuine, authentic speech using English as a second language. All the lessons were conducted after the

\footnotetext{
${ }^{1}$ Van Lier clarifies that an icon only resembles an object or the source of the information.

${ }^{2}$ Pierce $(1992,1998)$ uses "interpretant" to refer to the meaning of a sign.
}

participants' regular day-time school. The participants and I met for two hours each week. Participant observations, field note-taking and video-recording were employed as the research methods.

In the 12 lessons, the participants were given unique opportunities to co-constructing L2 learning activities with me. Since none of the activities in the program were influenced by the mainstream school curriculum, we coconstructed various language-based activities with a high degree of freedom. It also gave the participants chances to participate in many teacher-guided activities that they had never experienced. For example, in a class long before the research began, we had a group discussion about a news article all the students had shared. One of the participants suggested writing a letter to the editor of an Englishlanguage newspaper since he wanted to express his opinions about a news item. When all the other students seemed worried about the scope of work and the difficulty of the task, I presented a work flow chart to explain how we could accomplish the goal step-by-step. While some objectives were set by me, some emerged through discussions between the participants and me.

Besides the above activities, the participants and I had been doing various activities for more than four years before the research including show and tell, board games, watching English-subtitled movies, book reading, story retelling, individual presentations, news article sharing and group discussions as well as some written assignments like book or news article summaries and reflections. Not all of the activities were done in each lesson. The activities chosen for a lesson depended on many factors. For example, at times we omitted the activity of show and tell since the students wanted to spend more time on a project; due to their school exams, they would leave out the written assignments; or whether to include a group discussion depended on how well all of them had prepared for the topic.

During the research period, some new activities emerged and some old activities were removed due to the emergence of new activities. In the 12 lessons, the four participants and I conducted the following activities: movie watching, news article sharing, group discussion, and a group project involving two podcasting talk shows with the topics of fusion energy and true supernatural stories.

\section{Analysis and Results}

In presenting results, text providing a brief description of the opening theme covered in each section is italicised. This style of presentation aims to serve the purpose of providing a pivotal focus of contexts for more ecosystemwide accounts of results to emerge.

\subsection{Genesis of Signs}

Semiotic signs began to emerge and to change meaningfully as information flowed through the mediating tool between subjects and objects. 
The theme in italics above is a contextualised phenomenon that arose when looking into the emergence of semiotic signs. It was first noticed when the activity of news article sharing emerged as a symbolic sign to my students when some iconic and indexical signs of this activity interchanged dynamically under my guidance. In one activity of news article sharing, for instance, Juno and John were required to share a news article that Juno had read at home. Under my guidance, Juno was asked to externalise his own mental understanding (or private speech in Vygotsky's words) when sharing some key points of the article with his peer partner. I also instructed John to raise some questions for Juno. On the basis of this guidance, the content of the news article that resembled the occurrence of a real-life event emerged as an iconic sign, and from there the sign represented a tool mediating the exchanges of information between Juno and John.

The iconic sign was also not static with respect to its informational dynamics. During this co-sharing activity, for instance, the dynamic nature of signs was experienced when the iconic sign was transformed into an indexical sign. At one particular time of the sharing activity, when the two students finished sharing some key words of the article, Juno took the initiative to ask what questions John might have. John asked: "Why did they record in the Internet?" Juno then realised from the question that John had some misunderstanding as to the content of the article, so Juno immediately replied: "According to the article, nothing in the Internet was 'recorded' but 'CAUGHT' and they were CAUGHT in the Internet". Also, when Juno clarified the point, he stressed the word "caught" instead of "record" by raising his tone and indexically pointing at the word in the article. After this clarification, John quickly restructured his question and asked again: "Then why were they CAUGHT in the Internet?" This exchange between the two students demonstrates that an indexical sign (i.e., the article containing a word which was misunderstood by John but indexically pointed out by Juno) could actually emerge from an iconic sign (i.e., the content of the news article resembling the occurrence of a real-life event) that contributed to the restructuring of John's question as a semiotic action.

Besides the transformation of an iconic sign into an indexical sign, the iconic sign (i.e., the content of the news article resembling the occurrence of a real-life event) could also be progressively turned into a symbolic sign. For instance, in the same activity of news article sharing, when Juno shared the word "alcoholics" with John who did not understand this word, this word functioned no longer as an iconic sign (i.e., one that resembled the real occurrence of people being alcoholic) but was immediately transformed into a symbolic sign when Juno uttered the word's conventional meaning. He said: "It means people who drink too much wine". Then he saw John nodding his head. It means that to Juno, in the context of sharing the word with John, the word was an iconic sign. But in the context of referring the word to its conventional meaning, it became a symbolic sign to Juno and John.

The above incidence of dyadic interaction also demonstrates a phenomenon of interest in two fronts. First, it shows that the conventional information of the symbolic sign could flow from one peer student to another (e.g., from Juno to John). Second, this informational flow or semiotic transformation was important to the students' L2 learning since it ensured a successful sharing of a conventional meaning with information to flow meaningfully from one peer to another as well as to facilitate informational contexts to flow more smoothly. The following subsection continues to consolidate the phenomenon of interest.

\subsubsection{The Sign Chain}

One ecosystem-wide aspect to extract from the mentioned activity is that information was found to flow within a set of interrelated signs. As a characteristic of the program, when this set of signs emerged within an activity, information became signs that could be transformed from one entity into another. For example, the news article first emerged as an iconic tool containing a certain amount of real-life information. After Juno extracted the real-life information from the article (i.e., reading under guidance and internalising information into mental understanding in L2) and retold it to his partner (i.e., externalising his mental understanding), the news article that first functioned as an iconic sign (due to the article's resemblance to a real-life event) became an indexical sign of a misunderstood word. This transformation was actually completed through the context of John's internalisation and the finger-pointing of Juno to the correct term (with accurate information). Since the two signs were related and both were embedded in the same context in a dyadic setting, the context (i.e., the internalisation of John's feedback and the figure-pointing of Juno to the correct term) was like a "chain" linking different signs together.

The chain did not just end at the indexical point. According to the findings presented above, a symbolic sign emerged and continued to be "chained" with the vocabulary item "alcoholics" as the symbolic sign was transferred from Juno to John.

I describe this activity-based semiotic phenomenon as the "sign chain" represented by Figure 2. The figure contains four nodes interlinked by three arrows. The topmost node refers to the source of information; the second, an iconic sign; the third, a symbolic sign, and the fourth, an iconic sign (note that where the signs are located from the second to the fourth nodes depends on the signusing contexts that link one node to the next along the sign chain).

As an additional note, the sign chain may also help explain how meanings grow with sign-using actions in an L2 learning environment. In Figure 2, it shows that information flowed from a non-living artifact (i.e., news article) to become an iconic sign containing real-life information, and from this to become some co-sharing (or internalised) information and finally reached some 
symbolic (or conventional) information - all along with a range of semiotic actions (i.e., reading of the article under guidance, sharing of the news article and then key points and vocabulary between peers) that facilitated the flow of information or meanings.

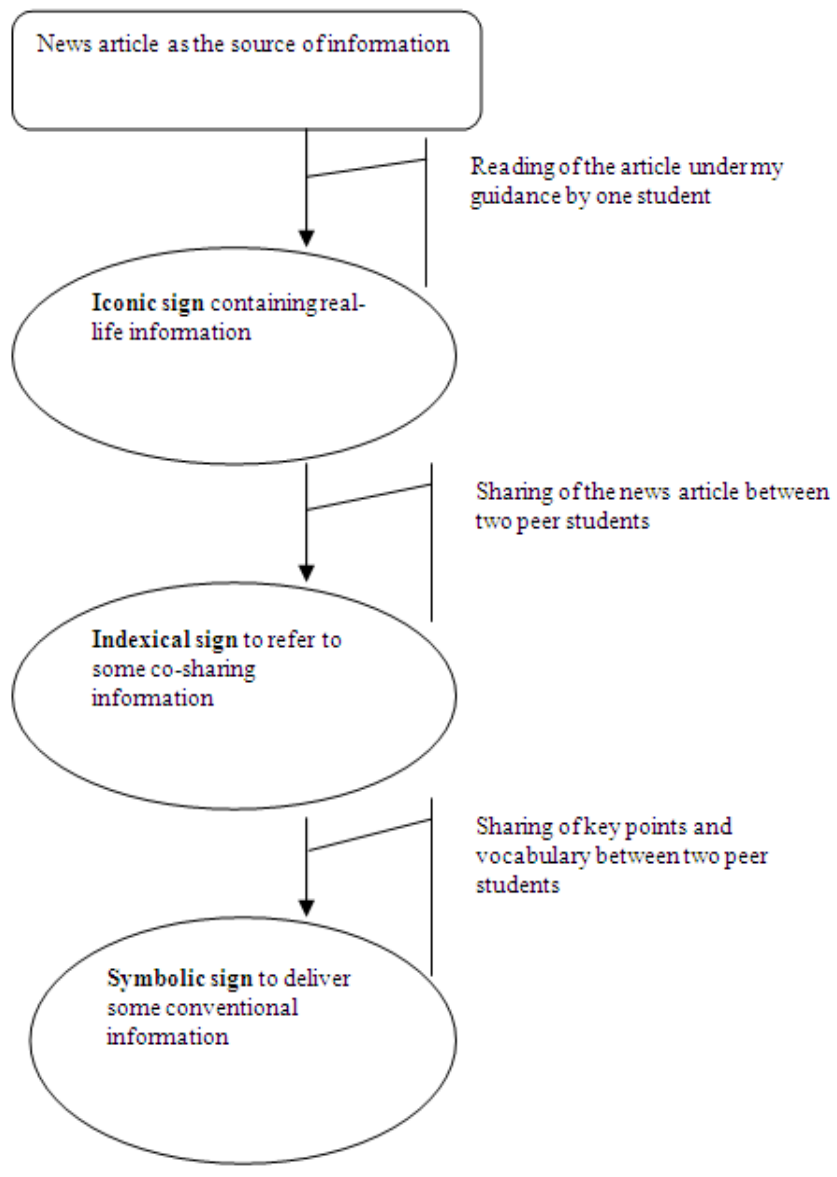

Figure 2.Sign chain

\subsection{Regulation of Signs}

When all the students and I joined an online website to become a community, signs were regulated by rules, aims and my guidance for meaning-making.

For meaning-making, emerged signs appeared to be under the direct influence of guidance so that the use of signs could be regulated by rules especially when signs were conventionally operated by a community. A set of details supports this.

In one activity, the students aimed to set up an online podcasting talk show. To this end, they needed to go through a lot of technical steps. One of the most critical steps was to upload some audio files to an online, Englishlanguage website called "www.ourmedia.com". This is a website specialising in audio-file storage for podcasting. Since the students and I were new to this technology, what I could do was to make sure that they had no problem understanding all the instructions set down by the website manager.

An iconic sign, when executed, can be transformed into a set of symbolic signs. For example, an icon called "Publish Media" on the website was encountered by Juno. He clicked on it, and immediately he was referred to a webpage containing some instructional information with a set of rule-based, symbolic signs. Representing some procedural information and actions the students had to take, the signs were what the student began to be aware of: "Alan, it is very important. We haven't read it yet!" said Juno after he and his brother, Alex, realised the importance of this piece of information.

To join the online website was the first step of the technical procedures. It was also a step we had to take for us and the website to become a community. Acting as a community gateway between us and the website, the language-based instructional rules or signs were what the students had to follow. Thus, the rules were signs because they represented some procedural information regulated by the online website.

Not following the rules would result in contradictions or conflicts between the activity and the relevant community (Engeström, 1987), and this was what happened to the students. A problem arose when the students overlooked an instructional rule - if an audio file exceeded 10MB, another software tool had to be used. This rule functioned as an indexical sign to point them to what they had to do - to study the uploading rules more carefully. But since they forgot where the uploading rules were exactly, I guided them to where they should look at. As such, my guidance contributed to their knowledge of the size-limit rule as an indexical plane on which the indexical sign (i.e., the instructional rule) could eventually pointed them to another source of information. After they went through all the instructional lines again, I had to make sure that they had no problem understanding them. With this further guidance, they carefully followed up with all the instructions step-bystep. Within 20 minutes, Juno told me they could finally upload an audio file to the website for podcasting. This was a hilarious and meaningful moment to them since they realised that they could understand all the instructions, master all the technical processes and, most importantly, their talk shows could be accessed at any time and from anywhere in the world. It turned out to be a highly meaningful activity to the students.

\subsubsection{The Blueprint of the Guidance Cycle}

To interpret the above results regarding the regulation of signs, I found further that another phenomenon of interest after the sign chain - a proper guidance system being essential for developing the students' L2.

This guidance system, based on the above results regarding the regulation of signs under an activity aim and guidance, was a vital component to mediating different aim-oriented tasks. With the activity aim to upload an audio file to a specific website, despite my not being an expert in this technical matter, my guidance was nevertheless very important in making sure that the students would have no trouble understanding all the textual-based procedures and 
that they could reach the aim of loading the audio file to the website successfully. As an ecological characteristic, my guidance with a wider angle (i.e., with an aim-oriented basis) related the students' actions to the aim of an activity over time, thus linking actions and the activity aim in an aim-fulfilling cycle. In this sense, the students' needs for my aim-oriented guidance through this guidance system is, for future reference, called the "guidance cycle". Figure 3 shows a graphical blueprint of the guidance cycle based on the above results. This figure contains a series of six nodes connected by five arrows in an anti-clockwise direction, thus forming a circular cycle. The topmost node in the middle refers to the aim of an activity. The two nodes connected to the left and right side of the "aim" node are the "guidance" nodes which refer to the teacher's aimoriented guidance. There is one more "guidance" node located at the bottle-most part of the cycle. This node serves the same guidance purposes as the other two guidance ones. The sides of this node are connected to another two nodes. The one on the left refers to the internalisation of information by a student, while the one on the right refers to the externalisation of the same information by the same student. In overview, this guidance cycle shows how a teacher's aim-oriented guidance guides a student through internalisation and externalisation of information and relates a student's semiotic actions to the aim of an (L2 learning) activity.

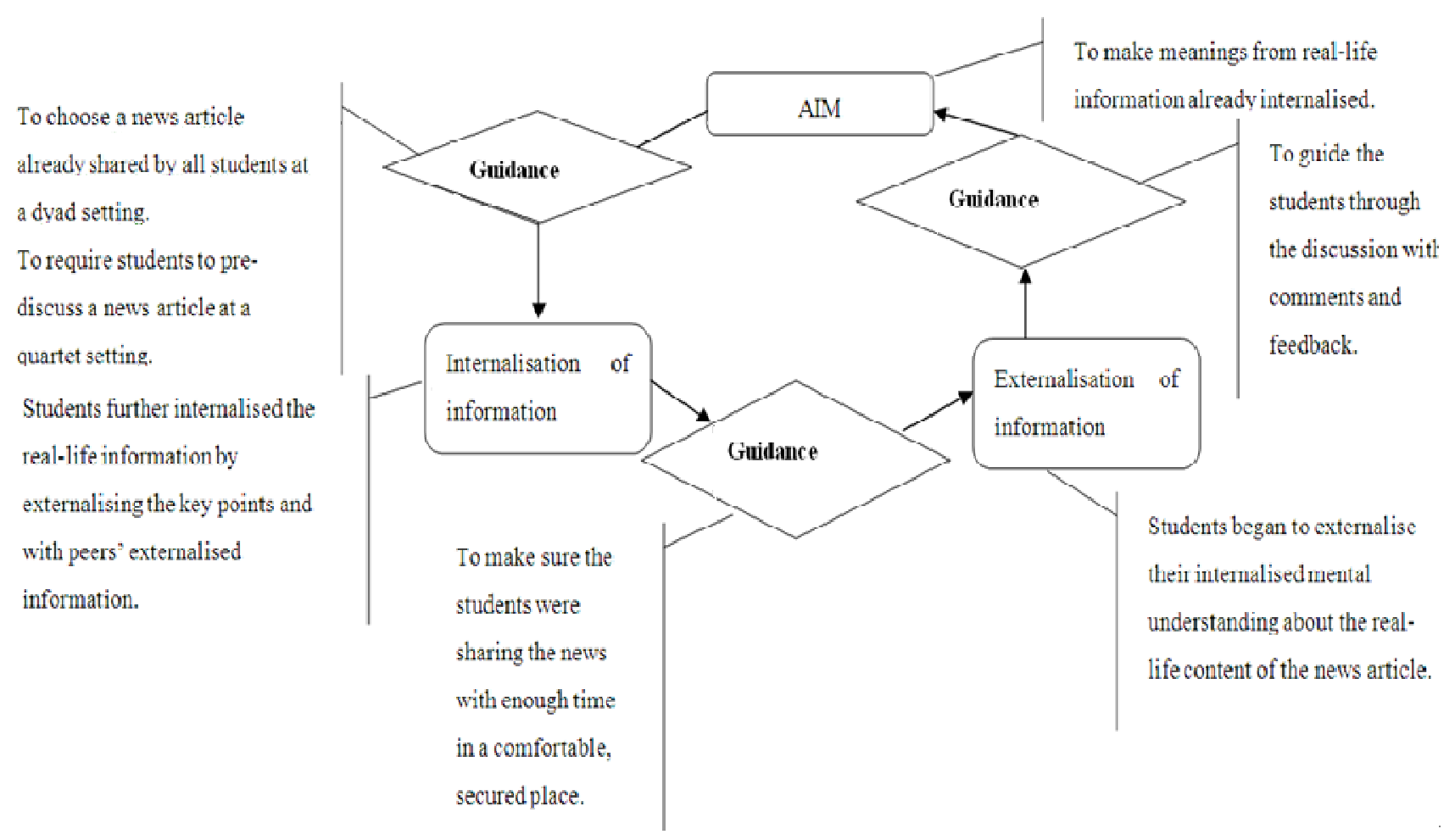

Figure 3.Blueprint of guidance cycle

\subsubsection{The Guidance Cycle}

The results presented previously regarding regulation of signs and the guidance cycle were under the aim of a podcast set-up goal. This section turns to purely a language learning one. It is for the purpose of bringing up a picture that suits the main theme of the paper (i.e., understanding the essences of L2D in an ecological approach). To this end, I revisited all the raw data and obtained further details to enhance the understanding of the guidance cycle by relating the realisation to a semiotic goal.

Based on a set of extracts from the tenth lesson, Table 1 was used to organize and analyze the data. It was an intermediate procedure before fitting the data to the picture of the guidance cycle. In this table, I tried to fit selected details (i.e., "Content of activity" in the right column) to the aim of the activity, the activity actions of my guidance and the students' internalisation and externalisation of information on the right column. The last cell of the left column refers to the results of meeting the aim. This is an important part of analysis since it helps confirm that all the actions along conform to (or are related to) the aim of the activity.

In this lesson the students and I conducted a group discussion activity. In this activity, the aim was to create an environment in which the students could make real-life meanings using their L2 with some real-life information already internalised. 
Table 1. Key to analysis of guidance cycle of group discussion activity

\begin{tabular}{|c|c|}
\hline Activity & Content of activity \\
\hline Aim & $\begin{array}{l}\text { The aim of this activity was to develop my students' ability to use some familiar (i.e., internalised), real-life information } \\
\text { to generate some meaningful speech. }\end{array}$ \\
\hline & $\begin{array}{l}\text { The news article sharing in this lesson had one more aim. Since I found that they had one article that had already been } \\
\text { read by all of them, I picked it out and told them that we could have a group discussion about the article among the five } \\
\text { of us. }\end{array}$ \\
\hline Guidance 1 & $\begin{array}{l}\text { But since I wanted them to have a better contextual sense of the article, I asked the four of them to go through some of } \\
\text { the key points first before the group discussion. I considered this pre-discussion a chance for them to perceive a } \\
\text { collective understanding of some real-life information from their peers directly before generating their meaning-making } \\
\text { speech at an individual level. }\end{array}$ \\
\hline $\begin{array}{l}\text { Internalisation of } \\
\text { information }\end{array}$ & After 15 minutes of sharing among the four students, they came back to the dining room where we began our discussion. \\
\hline Guidance 2 & $\begin{array}{l}\text { During the pre-discussion, I saw them sitting in the living room comfortably. I also saw them take out some soft drinks } \\
\text { to enjoy when pre-discussing the article with each other. I allowed them to do this since I wanted them to enjoy the time. }\end{array}$ \\
\hline $\begin{array}{l}\text { Externalisationof } \\
\text { information }\end{array}$ & $\begin{array}{l}\text { John was the first to speak. He asked whether they thought that teenage children using the Internet too much was a } \\
\text { serious issue. Then they spent some time reading the article again. Before the sharing came to the end, Juno said people } \\
\text { should have a normal social life like them. After } 15 \text { minutes of sharing among the four, they came back to the dining } \\
\text { room where we began to discuss the issue. }\end{array}$ \\
\hline Guidance 3 & $\begin{array}{l}\text { During the discussion, I talked about the importance of the Internet while the children focused more on the various } \\
\text { reasons why many teenagers became addicted to it. } \\
\text { Right after John brought up the point about teenagers' time management, I gave the feedback that my own cousin was } \\
\text { also having time-management problems due to the overuse of the Internet. }\end{array}$ \\
\hline Results to meet the aim & $\begin{array}{l}\text { Their collective explanation was that the culprits were mainly the online games and MSN chatting. But they also agreed } \\
\text { that there was a positive side of the technology. At an individual level, Alex's main concern was that using the Internet } \\
\text { too much would damage brain cells. John and Juno exchanged their ideas that health and online gambling should be the } \\
\text { main concern when considering this issue. And more specifically, suggested that teenagers could think of some positive, } \\
\text { healthy things to do besides using the Internet. John added that time management by today's teenagers should be also an } \\
\text { issue of concern. }\end{array}$ \\
\hline
\end{tabular}

After using Table1, I put together the details and formed the guidance cycle of the group discussion activity as shown below in Figure 4.

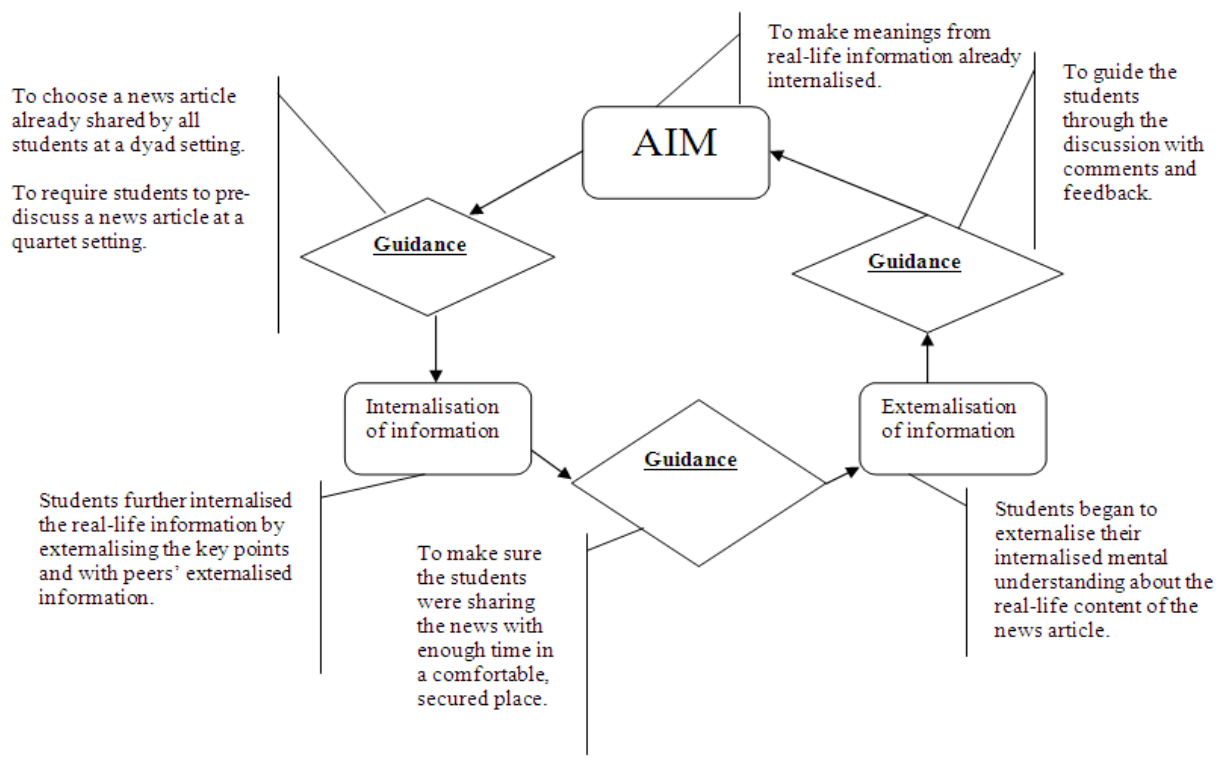

Figure 4. Guidance cycle of the group discussion

Figure 4 shows that my guidance (i.e., to require my students to pre-discuss) again mediated my students' semiotic activity by regulating their semiotic actions/interactions (i.e., internalisation and externalisation of real-life information or key points for meaning-making in both dyadic and quartet settings) from node to node. An important aspect to underscore regarding this mediation of regulation is that since my guidance was aim-oriented (i.e., to let students make meanings from real-life information already internalised), the students' semiotic actions were developed closer and closer to the semiotic aim. Therefore, I further realise that, in a guidance cycle, whether a teacher's guidance is aim-oriented or not critically determines whether students' learning could attain a certain expected goal. To finalise this realisation, I develop a schematic model of the guidance cycle for future references, as shown in Figure 5. ). 


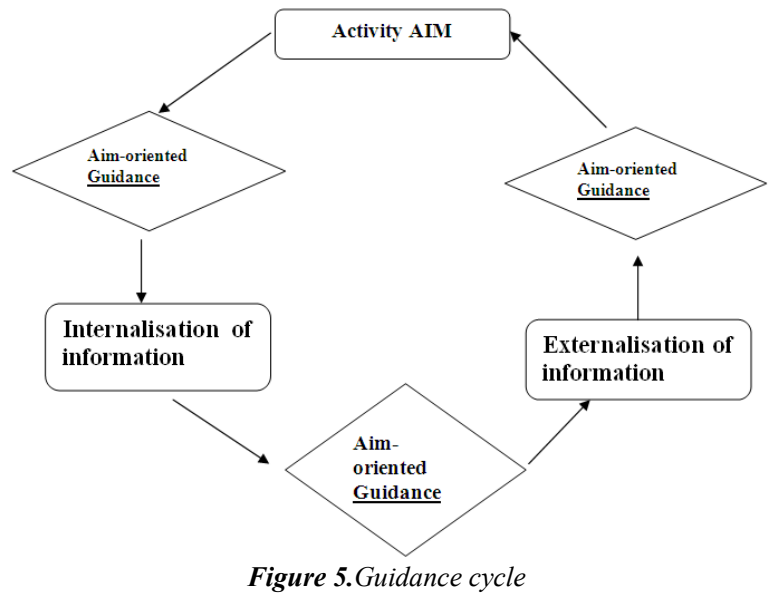

Based on the results generated above, it seems that the guidance cycle is situated between Vygotsky's ZPD and Engeström's (1999) activity theory. The former highlights the significance of guidance for learners' learning development while the latter situates an activity in a goaloriented context. When ZPD is contextualised in an aimdirected activity, it should not be difficult to see that when an adult's guidance is aim-oriented, the learner's development will be directed closer and closer to the aim of an activity.

The closer-and-closer-to-the-aim aspect can also be considered as an expectation that deserves a further look with van Lier's (1996 \& see also 2004 and 2007) theory on macro-meso-micro scaffolding. First of all, as van Lier points out, any successful activity flows along a threelayered scale in terms of interactions and contexts that limit how interactions occur. Scaffolding in activity is assisted (Bruner \& Sherwood, 1975) while van Lier indicates that scaffolding is not only assisted but, within a learning objective agreed or perceived by both the teacher and learners, "constrained" and "neither predicted nor controlled" by the objective (van Lier 2004, p. 149). That means the exact interactional details of a learning activity (at a micro level) are "constrained" by how the interactional details should be performed (at a meso level), and both the micro and meso details are ultimately further "constrained" by what the interactional details over time should end up to be (at a macro level). Using this theory of layered constraints at different scales, an experienced teacher provides meaningful signs at a macro level that a learner can choose to use at a meso level in order to maintain their attention for their learning actions at a micro level. Van Lier's contribution to this aspect of scaffolding theory therefore leans on how learners" "awareness" can be maintained in a meaningful activity (see van Lier, 2007, p. 61 ). In contrast, the guidance cycle is more of a concern with the teacher's mindfulness in that students' interactional details cannot be predicted but can be expected if the teacher's guidance is aim-oriented throughout the macro, meso and micro levels. In practice understanding expectation is useful in developing teachers' competence of teaching.

\subsection{Distribution of Signs}

Signs were distributed on the basis of a division of labour for a particular goal. Distribution of signs was found to be in this way a dynamic force facilitating the creative use of signs and the accomplishment of a semiotic goal.

In the study, the division of labour was found to distribute signs on different semiotic planes symbolically, indexically and iconically. First, signs could get distributed with an "iconic plane of arrangement" through a division of labour. How does it all work? What does "iconic plane of arrangement" mean?

In one lesson, Alex and Frankie were working on two different computers, sitting side by side with a one-bodywidth gap in between. Again, they were working on the podcasting project. Alex was at that time preparing a document for a talk show while Frankie was reading something on a website about fusion energy. They sat quietly there without knowing what the other was doing, let alone sharing information with each other. Worried that they might not be working on the same goal, I encouraged them to work together and share what they were doing with each other from time to time. However, there was still nothing between them except silence. To break the silence, I assigned Juno to stand behind them and observe what they were doing. In this arrangement, Juno became like an icon that resembled a bridge or a mediating agent between Alex and Frankie. I told the two students that Juno's job was to make sure that they could share information with each other and work on the same goal more interactively. As a result, this iconic plane of arrangement was found to be effective when I saw the three of them share information with each other, especially, when the students encountered the animation process (i.e., an animated model) of fusion energy together. When they all looked at it, they began to discuss what elements were involved in the process of producing fusion energy. They even argued about what the elements should be with a surprising beginning:

Alex: I see an animation. Wow...so beautiful.

Juno: Wow...[laughter].

Alan (the teacher): What's so beautiful?

[Loud laughter from all the students]

Frankie: Uranium... to make helium and one nitrogen.

Alan: Is it a process about fusion energy?

Frankie: Of course.

Alex: Not nitrogen. Neutron.

Frankie: Nitrogen. No. Nitrogen.

Alex: [Point at the screen]. It is neutron.

Frankie: Neutron? Okay!

This interaction among them demonstrates that their L2 developed with a higher level of understanding about the topic of the talk show. It also implies the difficulties of promoting information sharing in a silent environment. Silence, however, could be shattered, as seen in this study, 
with a subtle change in the division of the labour. In this activity, Juno acted as an icon representing not only a bridge between Alex and Frankie, but, as a result, a successful silence breaker who at a certain point in time broke the silence that had developed. It also brought up a meaningful contribution to the overall context: Alex and Frankie began to share, which led everyone to a better understanding of a chemical reaction, extending beyond the knowledge level of their teacher.

As a note for discussion, this result adds some support to Engeström's (1999) notion that contradiction or conflict happening in an activity is an opportunity for a higher-level development. The current result showed that the conflict between my requirement to collaborate and the insistence on silence by Alex and Frankie reflected a flaw in the arrangement that facilitated some changes that later led to some major development for the overall context of understanding. Besides that, the setting of the environment and the availability of labour allowed me to assign Juno to stand between them. This division of labour was realised to promote a meaningful sharing and some constructive conversations among the students. It also helped them comprehend an L2-based, scientific concept together at a higher level of understanding. In this case, a conflict provided a vital context for promoting students' language learning development; the way the conflict was handled contributed to a dramatic transformation of the entire learning environment.

The above set of details is an example showing how information was distributed on the iconic plane. But according to another set of details, signs of information were not inherently distributed on the iconic plane of arrangement, but the symbolic plane of conventional meanings as well as the indexical plane.

In the L2 learning program, one role of mine was to function as an information provider, providing meanings of English in their conventional sense. It was therefore, on this conventional plane, that I provided a symbolic source of information for the students. For example, in the preparation work for the podcasting activity, the students found a lot of reading materials on the Internet about the topic of fusion energy. Although they did not seek any information about fusion energy from me, they needed me to provide some conventional meanings for the vocabulary they were not familiar with. "Actinides", for instance, was the term they asked when they tried to understand how good fusion energy could be to the environment. At that time, Alex, Juno and John were together reading an online article about fusion energy. They all looked at the same desktop monitor screen, and I was standing behind them, observing them while writing some field notes. The following excerpt demonstrates how signs were distributed from a symbolic plane of beginning:
1. Alex:
Alan, what is Actinides?
2. Alan:
Can you say it again?
3. Alex:
"A...c...t...i...n...i...d...e...s"
4. Alan:
To be honest with you, I also don't know

what it is exactly since it is a technical name of a chemical. But we can tell from the context that it is something not good. It is... it is... you know... it says fusion energy is very safe, right? Fusion energy is very safe because there are no chain reactions and no production of actinides. That means this kind of stuff is not safe. Since there is no production of this kind of substance, that is why fusion energy is safe. Ok? Now it is a good example. You know what I mean? We can...We don't need to know the very technical stuff, but we can learn through the context. The context is why it is not good because... (I raised the tone on "because" and turned my head to John.) (2 seconds pause)

5. John: It won't produce any chemicals.

6. Alan: It won't produce any chemicals, so it is very... (I raised the tone on "very" and turned my head to the side of Alex and Juno).

7. Juno: Safe.

8. Alan: Safe. Now this is the point. What you need to know is just this context about a word you don't know. And now I want you to rephrase it. Now you can say, for example, fusion energy is good because it doesn't produce any harmful substances like actinides.

Line 1 shows that with a question in mind about the conventional meaning for an English word Alex wanted to look for. Rather than guessing on his own, discussing with his partners or looking it up in a dictionary, he immediately hopped onto the symbolic plane (i.e., looking for the conventional meaning of a word). But to me, since I also had no idea of the exact conventional meaning of this technical term, what I resorted to was the context of the vocabulary, "Actinide", on an indexical plane. On this plane, I found that the context (i.e., "Fusion energy is very safe because there are no chain reactions and no production of actinides") directly pointed the word, "Actinide", to the information that it should mean some kind of "harmful substance". At this point, I tried to guide them through the context to find out the meaning of the word. Under my guidance on the indexical plane (see line 4), they managed to locate the indexical sign of context and made use of it to obtain some meaningful information related to the word (see lines 5 to 7 ). In line 8 , I rounded up the resulting meanings and let the students collect them for a better understanding of the context. In this activity, signs were, through a division of labour, distributed among the information provider (me), the students as an information inquirer (Alex), information interpreters (John and Juno) and information collectors (all the students). On the symbolic and indexical planes, this division of labour dynamically distributed information in the way that all the information was first forwarded to me on the symbolic plane by the information inquirer; the information of the indexical context of sign (i.e., the context of the word, Actinides) was identified by me as an information provider to provide proper contexts of information for the students; the information was further interpreted under my guidance on the indexical plane by the information interpreters; and finally the exact information containing some conventional 
meanings of the word flowed to the information collectors who needed the information to understand what they were reading for the podcast talk show activity. As an ecological characteristic, signs were distributed according to the division of labour on different planes of semiotics. All in all, this set of details provide further support to the notion that meanings (of an English word unfamiliar to a learner) could grow along a number of sign-using actions.

\subsection{Usage of Signs}

Signs were used creatively on different planes of semiotics when team efforts were oriented to accomplish a semiotic goal as an outcome.

During the twelve lessons, two podcasting talk shows were produced by the students. To the students, the goal of the activity was to produce two talk shows with different topics. To me, it was to create an online platform for all students to act on, to put their L2 to real use, to let the students produce meaningful information, and to share it with the rest of the world. After the students had produced the two talk shows successfully, I realised that the accomplishment of the goals also meant a great deal of L2based productivity on the part of the students.

When looking into my students' productive efforts further, I found that the context constructed on three planes of semiotics, including the indexical indication of information, the symbolic cues of representation, and the iconic transformation of students, was essential to an ecosystem-wide realisation. A set of findings involving the three planes of semiotics in relation to the development of the students' L2-based productivity offers some details to reflect the result.

When capturing the scenes of preparation work during the podcast project, I found that one part of the team efforts was oriented on the plane of indexical information. First, the students formed a habit of searching for some Internet hyperlinks that represented some websites containing some potentially useful information. Those hyperlinks therefore acted as some indexical signs pointing them directly to some locations in virtual space. Besides the hyperlinks, further indexical signs helped them pinpoint which parts of information on a website would be truly useful. For example, the headings of some online articles about fusion energy or the titles of some supernatural stories were exactly the signs that possessed this indexical function pointing the students to some expected information. In "Wikipedia" (i.e., an online encyclopaedia), the students managed to look for some headings or key words they expected to find. To search for some information about fusion energy, they typed in the key words "fusion energy" in the search field and, within a second, an online article with the exact heading of "fusion energy" as well as some relevant illustrations popped up. After going through the information encountered, the students were better able to connect with the highly abstract concept of fusion energy. The following excerpt from my field notes and transcription of the video data demonstrates how they appreciated what they found:

Alex reports to the others the information he has just found, which is about a reactor for fusion energy. They are greatly surprised when they see some real-life photos of a fusion energy reactor.

Frankie: $\quad$ It is the beauty of science.

Alex: It is so beautiful.

This shows the power of an indexical sign to ultimately increase the students' understanding and appreciation of some information. Similar to Wikipedia, the students often used "YouTube", a website containing and sharing a vast volume of video information in the Internet communities worldwide. In this supportive context, they used YouTube to look for some supernatural stories that they believed to be real for the last talk show. Like Wikipedia, YouTube provided a search engine that allowed the students to type in some key words. In this way, they encountered some videos about supernatural phenomena that they believed to be real. For instance, they found a seven-minute video clip which was claimed to be a real supernatural story spoken in Portuguese but with English subtitles. As well as video clips, the students also obtained a lot more useful information from English-based, textual information. For example, on "Psychic.com.hk", a website found by Google's search engine, the students found a lot of textual information or supernatural stories that they believed to be real.

How the students determined whether the stories they encountered were real or not was not done by blind belief. Each of the stories that the students chose for the talk show was carefully judged on an indexical plane where they particularly found some indexical signs of truthfulness. For example, a story called "Grey Light Shadow" was not chosen since "it provides not enough evidence"; "The Man in the Park" was not good since "it has nothing supernatural"; "Whispering Blue Face" was not convincing enough since Alex and Frankie found no detailed evidence for it; and "Ann's House" was considered not appropriate since Juno thought it was simply impossible for it to happen. As for the chosen stories, "iPod Glowed" was good since Frankie thought the story was told "with a lot of meaningful details", and "Opening Door" was considered by Alex to be good since there was some real-life evidence that "the house was burnt down".

Indexically, all the stories had a specific title that oriented the students to different stories containing further useful information. Besides tuning into the indicational information of titles, the students were actively engaged with more indexical signs that could point them to some stories they believed to be real, such as real-life evidence, meaningful descriptions or any supernatural details. Therefore, from the students' search work, the content, titles, headings and even a search engine field were all equally useful in the sense that when they were actively engaged on an indexical plane, they were transformed into some indexical signs that could provide the students with more appropriate information for meaning-making. 
Another part of the team efforts was devoted to transforming signs, for meaning-making, from an indexical plane into a symbolic plane through internalisation and externalisation of mental understanding. This is an important step since during this process the students needed to consolidate what information to use for meaning-making from a vast amount of indexical information. For example, before the talk show about fusion energy, the students tried to consider what points to talk about. To facilitate this work, they created a document with all the key points they wanted to raise during the show including how cheap the cost would be for the raw materials to produce fusion energy, how safe it was to the environment, and how inexhaustible the supply would be to meet the ever-increasing demand for energy. The information obtained from the virtual environment was in fact conventional and thus symbolic to the students since it had been well-established and socially accepted in the real world. To remind themselves of the symbolic content of information, they composed three questions as some symbolic cues to guide themselves through during the talk show: "What is fusion energy?", "Why is it important?", and "What effect will it bring to the natural environment?". In this way, the questions also became some symbols representing what they wanted to say. After all the indexical signs from selected websites were transformed into some symbolic signs on a document, the students internalised the content and further transformed them, in their minds, into some mental understanding which they later externalised in the talk show. The following excerpt of a discussion about the prospect of fusion energy that occurred during the second podcast talk show demonstrates how signs were transformed and externalised for meaning-making.

1. Alan: What is the prospect of fusion energy?

2. Juno: [Holds up the document, takes a quick look at it, and begins to speak without looking at it] There could be no future for fusion energy!

3. Alan: But why... Why do you say that Juno?

4. Juno: Ohm...because we just realised it according to the website. [Alex hand-signalled Juno to pass him the microphone.]

5. Alex: He [a scientist] wrote a passage on the web...

6. Alan: $\quad$ Ok...

7. Alex: And he said that because first human technology is so good...

8. Alan: $\quad$ Right...How about the future prospect...

9. Alex: Also because the cost is very high. If you continue to develop it, the cost will...higher, higher, higher, and higher. And sooner or later, we will not be able to afford it. So the future of fusion energy will not be good.

10. Alan: But theoretically would it be possible to have fusion energy if the scientists really continue to study it? Would it be possible? To make it really happen someday?

11. Frankie: I think theoretically fusion energy can be used because in the universe the sun is using this energy, this kind of energy.
12. Alan: Oh! That is a point I want to make. Thank you! You said it is based on how the sun works.

13. Frankie: Yes!

14. Alan: I see. Ok...so the idea is basically from the sun. Are you saying we are trying to recreate the sun? On earth? That is why it is so hard to make it?

15. Alex: Yes, because the temperature is so high for fusion power. So it is hard to...

16. Alan: To contain...

17. Alex: To contain it. Yes.

Based on the above dialogues, the students acquired the conventional (or scientific) knowledge of fusion energy provided by a scientist from the virtual environment (see lines 4 and 5). This acquisition was the result of managing to internalise the conventional knowledge into their own mental understanding and to externalise later when an appropriate time arrived. The externalisation came in two fronts. First, they turned all the necessary knowledge from a website into some symbolic sets of textual information on a document. Another call for this externalisation can be seen in lines 2, 7, 9, 11, 12, 15 and 17 of the above excerpt when the students and I exchanged information about fusion energy. Especially in line 11, Frankie used "I think" which was a trace of evidence showing that he had already internalised some information before externalising his mental understanding regarding what he thought about fusion energy. As a result, I found that the transformation of signs from indexical into symbolic could be a semiotic context for the students' internalisation and externalisation of understanding in L2.

Before moving on to the third aspect concerning the iconic dimension of semiotics of the usage of signs, a particular point needs to be discussed since it is centrally related to Vygotsky's language development theory.

According to Vygotsky (1978), higher language development is a result of internalisation and externalisation of mental understanding. Lantolf and Thorne (2006) add that what can facilitate internalisation and externalisation of mental understanding is an environment in which children are given the opportunities to use their mental understanding of L2 and make meanings actively. Based on the above set of details, I would like to extend the point that the environment would be more enriched if children were given more opportunities to develop their mental understanding of L2 by actively encountering, manipulating, recreating and transforming indexical signs into symbolic signs. This kind of environment, as seen in the current study, was helpful for my students to externalise their mental understanding to encounter more meaningful contexts for further semiotic actions. For example, my students were given a high degree of freedom to encounter a wide range of indexical orientations (e.g., story titles, website headlines and some specific details of content) for further actions to go on with. Also, they were allowed to manipulate what information should or should not be used for further internalisation (e.g., to determine what supernatural stories should be considered 
true). Also, they were provided a setting in which they could create or recreate any sources of information for their own use (e.g., the document they composed with all the key points or cues). And, in this manner, how they condensed conventional knowledge into some symbolic cues was vital for their further semiotic actions or development.

The third aspect regarding the usage of signs is that each of the students in the talk shows was transformed into an icon representing what points to say or what stories to talk about. It is like the role-playing activity in drama that first assigns script information to all roles to be played. But different from drama, the podcast project activity has a more flexible, real-life role to interact with. It is more flexible in the sense that the talk show production would not become a fixed style like drama (although both activities begin with a pre-arranged set of information for internalisation and externalisation). In this way, the externalised speech could reflect each student's internalised understanding of L2 more truly since the externalised speech of drama would be merely a result of memorisation. For example, in the second podcast talk show, the students were expected to speak like an expert on fusion energy. This expert-like role was confirmed when their mental understanding was meaningfully uttered in the talk show. The excerpts of details about the prospect of fusion energy below demonstrate the significance of their iconic roles:

Alan: How about weapons based on fusion energy?

Frankie: Oh! In fact, hydrogen bomb is based on fusion energy.

Alan: Oh really?

Frankie: Yes, but its size is much smaller than the nuclear bomb.

Other students also featured their expert-like knowledge with their own specialties. For example, Juno and Alex developed a sense of their own technical opinions about fusion energy and the environment:

Juno: I think...hmmm...although fusion energy will not be used in the near future, it is still worth to study it since would not lead to any air pollution or harm to the environment.

Alex: I think fusion energy is worth to study. Nowadays, global warming is getting worse and worse. The main reason is that the green house gases produced are caused by deforestation. If people keep on using coal and coalenergy generators, or that kind of thing, more green house gases will be released. And it will destroy our environment. Soon all humans will dead.

Alan: Will die out.

Alex: Yes, so for the future of mankind, it is worth to study.

John's iconic representation of some economical concern about fusion energy was also obvious:

John: I also think it is worth to develop fusion energy. Although we have many choices of renewable energy like solar energy, they release much less energy than fusion power. So we can save a lot more money for the long run if we have fusion power. So that is why it's worth to study it.
As clearly shown from each student's utterances above, the iconic roles were a significant gateway through which their knowledge about fusion energy was first internalised and then externalised with the addition of their specified opinions. This kind of externalised utterance was thus developed in its semiotic complexity when symbolic information (i.e., the conventional/scientific knowledge of fusion energy) was further used on the iconic plane of semiotics.

In this section, we could see that internalisation and externalisation of semiotic information occurred not on a single layer of context for meaning-making but were embedded in three layers of semiotics - indexicality, symbolicity and iconicity. On the multilayered context, information took different forms of signs while being engaged actively. For example, during the second talk show, indexical signs pointed the students to a designated site of information where they encountered further indexical information from a more pinpointed location. On the indexical plane, they obtained a collection of symbolic signs containing an abundance of conventional knowledge. And on the symbolic plane, the students further organized and transformed the topic-related information into some symbolic cues for further internalisation and externalisation. Finally, on the iconic plane, all students acted as an iconic sign to each other during the talk show, further internalising and externalising information supported by the document they had prepared and, more importantly, the information they uttered and exchanged with each other to make further meanings.

Based on the above results, the next subsection continues to present how internalisation and externalisation of information on the multi-planes of sign-using resulted in another ecosystem-wide phenomenon of interest.

\subsubsection{Information Recycling}

The multilayered context where internalisation and externalisation were found to occur, as noted in the previous section, also extended its significance to three what-ifs for ecosystem-wide interpretations: on the iconic plane of sign-using, what if information never got exchanged, shared or used by the students? On the indexical plane, what if information was never encountered by the students? Or on the symbolic plane, what if information obtained was never actively engaged by any semiotic actions?

To infer in a logical sense, I would deduce that internalisation and externalisation would hardly ever or never occur. Not only this, information would become static as no one ever encountered or became engaged with it, and its dynamism would be limited since information would hardly get transformed from plane to plane. Even on the same plane of semiotics, the flow of information would probably stop when actors stopped internalising and externalising the information, let alone exchanging it between them. Since information could not act alone without actors' semiotic actions, it would stop flowing or 
even become wasted for meaning-making. An important concern arising from this thinking is that if information could not act on its own and must be encountered, exchanged and/or engaged for its semiotic survival (i.e., to continue its semiotic growth so as to reach the goal of meaning-making), would there be an ecological mechanism in humans' social activities (or in the ecology under concern) to preserve information, especially the information encountered and found meaningful, for semiotic survival?

Two arguments arise to address this question. First, humans' social activities are characterised by such a mechanism to preserve information so that it would not be wasted for meaning-making. Second, meanings might grow along sign-using actions particularly when information is encountered, exchanged and then internalized.

For example, the excerpts of details in the previous section about the prospect of fusion energy appear to indicate that information was not wasted - the information externalised by a speaker became the sign of information for another to further internalise and this was repeated in the same fashion:

(1)Information was first encountered from a website in the virtual environment and was used by Juno after he internalised and externalised it.

(2) Juno's externalisation then became the sign that was immediately "recycled" or "exchanged and then internalised" by Alex for further meaning-making purposes.

This sign also referred Alex to the information delivered from the website. After internalisation, he went on externalise his mental understanding and to utter his point of view about fusion energy. The end result was an accomplishment of the semiotic goal that everyone offered more opportunities for more meaningful contributions to the co-construction activity or each other's mental understanding in L2 over time.

The ecosystem-wide significance of this particular mechanism is that semiotic information was successfully "recycled" in the L2 learning ecology. This mechanism is referred to "information recycling" (see Figure 6).

This figure shows a series of five nodes connected by four arrows from top and straight down to the bottom. The topmost node refers to the source of information that a student attends to. The second and the third nodes refer to the internalisation and externalisation of the information from the source by the student respectively. Once the information gets externalised by the student, the information or sign is further internalised by another (or the second) student, as represented by the fourth node. This node also denotes the actual onset of information that gets recycled by another information or sign user. The bottommost node refers to the completion of the information recycling when the information was further externalised by the second student.

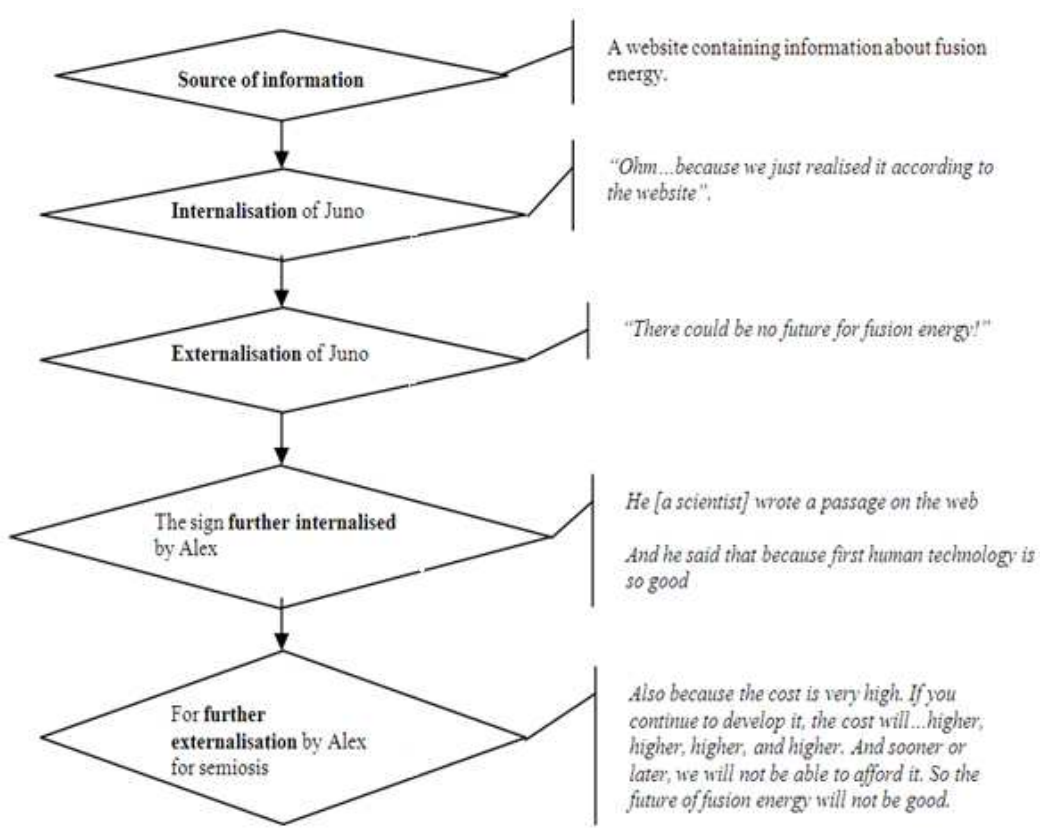

Figure 6. Information recycling

\section{Concluding Remarks}

The concluding ecosystem-wide results of the activitysemiotics analysis were that the patterns of sign-using and sign-making were diversified through the emergence, regulation, usage and distribution of signs for different semiotic goals. The diversity of signs was the context of the activity system's leading aim: to develop students' second language through internalisation and externalisation of mental understanding. In short, signs were the ambience of the eco-activity system, either physical or virtual, for linguistic development. As they were actively engaged by all the participants at the activity level, information flowed through the entire ecosystem, on the one hand, along the sign chains in which information was transformed in their 
semiotic nature by participants' semiotic actions and, on the other hand, was dynamically regulated by the aim-oriented guidance cycle in which the teacher's guidance brought semiotic actions and information closer and closer to some specific goals for meaning-making. In between the sign chain and guidance cycle lied with a process (i.e., information recycling) through which information maintained its dynamism - by being not wasted - when information internalised and externalised by one student was later further internalised by another student for further meaning making endeavours, thus increasing opportunities for the students' mental understanding of L2 to develop in semiotic complexity over time.

Adding more instances of complexity management to existing literature, this paper may reflect some strategic efforts to preserving any contextual data and reconstructing an L2 ecosystem in a systematic manner. However, what has been demonstrated in here may yet be fully addressed especially for an ecosystem-wide purpose. If an activity is seen as interrelations of signs carried out by individual actors, and if opportunities for students' mental understanding of L2 to develop increase over time, questions that concern, for example, how learners' individual actions function in terms of their perceptual actions as actors, how individual actors pick up information or how they act on signs for gaining a higher level of mental understanding resulted in L2 learning, remain untouched.

On top of the ecosystem-wide results of sign chain, guidance cycle and information recycling, this paper keeps on exploring and suggests how meanings might grow with progressive sign-using actions. However, further studies may still need to emphasize on, again, the individual perceptual-action side of issues and from there offer more evidence as to informing how meanings might grow with a learner's sign-using actions while uncovering more ecosystem-wide accounts of an L2 environment. On a practical side of concern, this type of supplementary study may help stimulate thinking on designing more meaningful L2 learning programs, tasks or interfaces that would give emphasis to the immediate (or pivotal) fit between students and proximal guidance, diverse information and active engagement as well as learning needs and teaching environment.

\section{References}

[1] Boer, N. I., Baalen, P. J., \& Kumar, K. (2002). An activity theory approach for studying the situatedness of knowledge sharing. Proceedings of the 35th Annual Hawaii International Conference on System Sciences. Retrieved from www.hicss.hawaii.edu/HICSS_35/HICSSpapers/PDFdocume nts/DTMKI01.pdf

[2] Bronfenbrenner, U. (1976). The experimental ecology of education. Educational Researcher, 5(9), 5-15.

[3] Bruner, J. S., \& Sherwood, V. (1975). Peekaboo and the learning of rule structures. In J. S. Bruner, A. Jolly, \& K. SyLantolf, J. P., \& Thorne, S. L. (2006). Sociocultural Theory and the Genesis of Second Language Development. Oxford: Oxford University Press.

[4] Buell, J. G. (2002). COWS in the classroom: Technology introduction and teacher change through the lens of activity theory. Retrieved from http://www.ed.uiuc.edu/meter/Documents/COWS_FollowUp. pdf

[5] Elleuch, N., Bellamine-Bensaoud, N., \& Ben Ahmed, M. (2006). Designing educational systems for use: Case study of Tunisian primary schools. Information and Communication Technologies, 1(24-28), 66-71.

[6] Engeström, Y. (1987). Learning by expanding: An activity theoretical approach to developmental research. Helsinki: Orienta-KonsultitOy.

[7] Engeström, Y. (1999). Perspectives on activity theory. Cambridge: Cambridge University Press.

[8] Garner, M. (2004). Language: An ecological view. Bern: Peter Lang.

[9] Gay, G., \&Hembrooke, H. (2004). Activity centered design An ecological approach to designing smart tools and usable system. Retrieved from http://mitpress.mit.edu/books/chapters/0262072483chap1.pdf

[10] Lantolf, J. P., \& Thorne, S. L. (2006). Sociocultural theory and the genesis of second language development. Oxford: Oxford University Press.

[11] Li, Y. (2013). Three ESL students writing a policy paper assignment: An activity-analytic perspective. Journal of English for Academic Purposes, 12, 73-86.

[12] Peirce, C. S. (1992). Selected philosophical writings: Vol 1. N. Houser \& C. Kloesel (Eds.). Bloomington: Indiana University PrPeirce, C. S. (1998). Selected Philosophical Writings: Vol 2. N. Houser \& C. Kloesel (Eds.). Bloomington: Indiana University Press.

[13] Peirce, C. S. (1998). Selected Philosophical Writings: Vol 2. N. Houser \& C. Kloesel (Eds.). Bloomington: Indiana University Press.

[14] Scalon, E., \& Issroff, K. (2005). Activity theory and higher education: Evaluating learning technologies. Journal of Computer Assisted Learning, 21, 430-439.

[15] Thorne, S. L. (2000). Beyond bounded activity systems: Heterogeneous cultures in instructional uses of persistent conversation. In S. Herring \& T. Erickson (Eds.), The Proceedings of the Thirty-third Hawaii International Conference on Systems Science. New York: IEEE Press. Retrieved from http://language.la.psu.edu/ thorne/cmchicss33.html

[16] vanLier, L. (1996). Interaction in the language curriculum: Awareness, autonomy and authenticity. London: Longman.

[17] vanLier, L. (2004). The ecological and semiotics of language learning: A Sociocultural perspective. Dordrecht: Kluwer Academic.

[18] vanLier, L. (2007). Action-based teaching, autonomy and identity. Innovation in language learning and teaching, 1 (1), $46-56$. 
[19] Vygotsky, L. S. (1978). Mind in society. Cambridge, MA: Harvard University Press.

[20] Wiredu, G. O. (2004). Chapter 4: Learning as an activity. December. Retrieved

from
21] Wiredu, G. O. (2005). Mobile computing in work-integrated learning: Problems of remotely-distributed activities and technology use. Unpublished doctoral dissertation, University of London. http://www.lse.ac.uk/collections/informationSystems/pdf/the ses/wiredu.pdf. 